Received: 2012.03.14

Accepted: 2013.02.13

Published: 2013.02.21

\title{
Couvade Syndrome among Polish expectant fathers
}

1 Institute of Psychology, University of Gdansk, Gdansk, Poland
2 Medical University of Gdansk, Gdansk, Poland
Authors' Contribution:

Study Design A

Data Collection B

Statistical Analysis C

Data Interpretation D

Manuscript Preparation E

Literature Search F

Funds Collection G

\author{
ABCDEF 1 Maria Kazmierczak \\ ABDEF 2 Bogumiła Kielbratowska \\ ADEFG 1 Beata Pastwa-Wojciechowska \\ DE 2 Krzysztof Preis
}

Corresponding Author:

Source of support:

Background: The aim of the conducted study was to analyze the phenomenon of Couvade Syndrome amongst fathers expecting their children in Poland. The authors examined the frequency of couvade symptoms in male subjects as well as their associations with male empathy.

Material/Methods:

The research involved 143 expectant fathers. All subjects attended antenatal classes, and their female partners were in their third trimester. Before the start of classes, participants were asked to fill in the following questionnaires: a survey for measurement of Couvade Syndrome (which includes a set of 16 symptoms identified by Lipkin and Lamb (19) and translated into Polish), and the Empathic Sensitiveness Scale (SWE). Although participants, on average, did not experience Couvade Syndrome, they did experience symptoms that are commonly linked with the syndrome, namely those related to weight (weight gain, changes in appetite and flatulence).

Results: The results indicate that expectant fathers experience couvade symptoms related to weight (weight gain, changes in appetite and flatulence). The only empathic component that positively correlates with Couvade Syndrome is personal distress, i.e. the tendency to take on the negative emotions of others. Demographic characteristics are not associated with Couvade Syndrome.

Conclusions: The frequency of couvade symptoms in male subjects is associated with male empathy. In other words, men who are emotionally sensitive or prone to distress may physiologically experience the pregnancy of their female partners, which can be interpreted as compathy.

Key words: Couvade Syndrome pregnancy empathy

Full-text PDF: http://www.medscimonit.com/download/index/idArt/883791

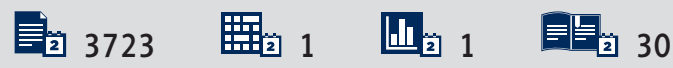




\section{Background}

The birth of a child changes the dynamics of the family system and modifies the mutual relations between parents. Therefore, the emotional reactions of both partners, not only mothersto-be, to the situation of increasing their family, should be examined. In this article the authors focus on the Couvade Syndrome experienced by expectant fathers. In the herein presented study personality and the social correlates of Couvade Syndrome are sought in order to comprehend the psychological nature of this phenomenon.

In European countries there is a trend to increase the commitment of fathers-to-be both during the process of pregnancy as well as in later child care [1]. In Poland more and more antenatal class centres are created to educate future parents on the situation of labour and caring for a baby. Nowadays there are almost 400 antenatal class centres in Poland and almost $25 \%$ of future parents benefit from their services [2]. In consequence, Izdebski believes that nowadays men are more self-aware of fatherhood and in extreme cases are at risk of Couvade Syndrome [2]. As a result we decided to analyze the phenomenon of couvade from the psychological perspective, since it should be noted that it is still relatively little explored with any relevant reports being focused on the analysis of the symptoms rather than understanding the causes and mechanisms of the phenomenon.

Couvade Syndrome is best examined from the anthropology perspective, which will be described below. To begin with, we should emphasise that the term "couvade" (from French "couver" - meaning to brood, to hatch) was first used by the anthropologist, Edward Burnett Tylor in 1865 to describe the child expectancy habits that he had observed among primitive communities [3]. The habit consisted of the man co-participating in and imitating labour pains, where he imitated the behaviours of the pregnant woman, withdrew from the work of his tribe, ceased his everyday responsibilities involving physical work or avoided sexual activity. The ritual also involved imitating the behaviours of a woman giving birth (such as staying in bed and crying loudly). The woman handed a newborn baby over to her husband, and he put it to his own breast, trying to emulate breastfeeding. The aim of such rites was to protect the baby and the mother against the powers of evil but also to make it possible for the man to establish a supernatural bond with the baby. As couvade habits were practised in a similar way in different cultures on different continents, it was assumed that this was a universal form of behaviour [4].

Additionally, Murphy [5] writes about two types of the couvade phenomenon: ritual and modern. The ritual form was practised as early as in ancient Greece, and is still found among so-called primitive societies The modern type refers to pregnancy-like symptoms which are observed amongst the partners of pregnant women. Munroe et al. [6]; cf. Broude, [7] distinguish two forms of the Couvade Syndrome, namely: 1) classical or extreme and 2) magico-religious. In the classic form, the father enacts a childbirth scene, imitating symptoms experienced by the mother, also in labour. However, as concluded by Munroe et al. [6] in their cross-cultural studies, the most frequently observed form is the magico-religious one, which is associated with a specific set of prohibitions for male behaviour such as a ban on hunting or eating specific foods. At the same time, on an unconscious level, the man is to go back to an identification with women. Expressing such an identification through the Couvade Syndrome is supposed to be motivated by perceiving women as those in control over socially desirable resources [6].

Taking the psychological and medical perspectives into consideration, research such as that by Kiselica and Scheckel [8] or Brennan et al. [9] on the symptoms of Couvade Syndrome emphasise gastrointestinal disorders, including in particular changes in appetite, diarrhoea and vomiting. Malaise and leg cramps are reported by future fathers too. Brennan et al. [9] stress that Couvade Syndrome is absent from DSM-IV and ICD-10 medical classifications, which indicates that it is not a mental or physical disorder but a natural phenomenon related to a partner's pregnancy. Nevertheless, in their subject literature review Brennan et al. [9] emphasise that it is possible to talk about a psychogenic or neurotic origin of the syndrome as its symptoms occur in the first or third trimester of the partner's pregnancy and cease after childbirth. They also mention the increased level of anxiety in expectant men and its research-confirmed link with symptoms of Couvade Syndrome. Couvade Syndrome is therefore a psychosomatic representation of typical female pregnancy symptoms, yet with a little explored physiological origin.

Couvade Syndrome has been linked with male empathic responses to female partner pregnancy/labour signs [10]. Although authors [10] acknowledge the emotional and cognitive components of empathy [11], they believe that physical side of empathizing cannot be omitted. As empathy is commonly defined as sharing emotions (usually negative) with another person [11], Morse [10] states that “(...) An emotion or feeling of distress cannot exist without various physical correlates or manifestations. (...)" (p. 54). They define such physical responses to others' distress as compathy, an example of which is Couvade Syndrome.

However, they [12] underline the need for a definitional distinction between the Couvade Syndrome and delusions of pregnancy - the latter refers to the situation when a man believes he is pregnant. According to the authors, differential diagnosis should, in the first place, consider the man's awareness that 
although experiencing symptoms typical of pregnant women, he is not actually pregnant. The aforementioned authors refer here to the theses that link Couvade Syndrome with neuroticism and male envy of the ability to give birth. Eisner [13] considers Couvade Syndrome to be an example of the loading phenomenon, i.e. taking on the suffering of others, primarily psychological but also physically manifested, and experiencing suffering-related symptoms until the other person is able to cope with the situation. According to Eisner [13], it is a very distinctive form of loading, as it is more frequent for women to take on the suffering of others. On the other hand, Kitzinger $[14,15]$ and Richman [16] point out that Couvade Syndrome is most widespread among men who are trying again to be themselves in a new situation. Pregnancy symptoms are most likely to occur when men are expecting the first baby, and the new situation makes them considerably anxious.

Men feel uncertain about the future in their new role as a father and are afraid of the family man responsibility, in particular for the baby. Healy [17] shows that Couvade Syndrome is more often observed in relationships where the bond between the man and the woman is very strong, which in turn is promoted by the very strong psychological and physical fusion between the partners. Considering Couvade Syndrome from the psychological perspective, it may be noticed that psychodynamic or psychoanalytical theories are often invoked [12], Murphy [5]. At the same time, the authors often refer to such concepts as envy of the act of childbirth, an unrealised need to create, strong identification with the mother, unresolved Oedipus conflict or treating the fetus as a potential rival to gain the attention of the female partner [12]; Murphy [5]. Brennan et al. [9] invoke theses from the literature stating that the awareness of child development may result in regression towards the greater need for dependence, which as such is in conflict with men's need for autonomy. Taking care of the child's mother and sympathetic pregnancy on the conscious level may actually mask unconscious hostility [5]. It must be remembered that the psychoanalytical model assumes, inter alia, the occurrence of developmental disorders of a symbiotic nature, where we create our own identity based on others. This results in conflict in terms of autonomy and enmeshment and as such may lead to the emergence of a dependent or borderline personality (B. Pastwa-Wojciechowska, 2009, personal communication).

An overall worsening of symptoms occurs during the third trimester of the partner's pregnancy [18]. The meta-analysis carried out by Brennan et al. [9] shows that the symptoms often surface in the first trimester and disappear in the second only to re-emerge and grow worse in the third trimester. Sociologists, in turn, draw attention to the social role assigned to men, namely of the observer of prenatal life and labour, which may exacerbate the stress and provoke the syndromerelated symptoms $[9,19]$.
Brennan et al. [9] found that the prevalence of the syndrome varies significantly depending on the research, ranging from between $11 \%$ and $97 \%$. For example, in the research by Lipkin and Lamb [20] involving a group of 267 men, $22.5 \%$ of fathers displayed symptoms of Couvade Syndrome. Statistically, subjects with diagnosed Couvade Syndrome sought medical consultation more frequently. Discrepancies in the statistics of couvade prevalence may result from the lack of a precise group of symptoms that determine the syndrome's diagnosis [18].

In publications on the subject, there is a discussion as to whether the prevalence of Couvade Syndrome depends on demographic variables such as age or education, and the results are often contradictory, giving no single and coherent answer $[9,8,18]$. However, Kiselica and Scheckel $[8]$ analyse the situation of teenage fathers as a group particularly vulnerable to experiencing Couvade Syndrome because of the unplanned nature of pregnancies, inadequate competence to take up the role of the father, stress and often lower education, pointing out to some the risk factors for this phenomenon.

The occurrence of pregnancy symptoms amongst men may be just a different form of the couvade ritual. Fathers simply need the rite of couvade and support after childbirth [21]. Expecting the child and the childbirth are together the most important moments in the life of the family and partners. However, in the era of institutionalised childbirth, it is not always possible to ensure that both partners share the experience. Fathers may prepare for the childbirth and accompany their partners during labour, yet afterwards they are still isolated from the mother and child [22]. Swedish research from 1974 [23] noted that preserving the couvade rite might have a beneficial influence on the manner of infant care at home, as it gave the father a sense of confidence. The creation of socially acceptable rites in the perinatal period would make it possible to define the father's role in a more explicit way.

\section{The aim of the study}

The purpose of the present research was to examine the frequency of couvade symptoms in male subjects from the psychological aspect, which has been defined primarily as a personality trait often linked with taking over other people's emotions or suffering, namely, empathy. The term compathy might be used here to describe male responses to pregnancy symptoms displayed by their pregnant partners [10]. It is worth noting that in the research presented here, Couvade Syndrome served as a dependent (endogenous) variable, while empathy is treated as an independent variable (exogenous variable). Associations were examined between the symptoms of Couvade Syndrome and such demographic variables as age, education, and marital status, which were included in the research model as additional independent variables. 
Detailed analysis included:

1. The symptoms of Couvade Syndrome and their frequency in the group of studied men.

2. The level and structure of empathy in the context of its connection with Couvade Syndrome.

Two main research questions were asked:

1. Do the male subjects report symptoms of Couvade Syndrome and how often?

2. Is the experiencing of Couvade Syndrome symptoms connected with empathy understood as a personality trait?

\section{Material and Methods}

The research was carried out in seven antenatal class centres in the urban conglomeration that is Gdańsk-Gdynia-Sopot and Puck in northern Poland between February and July 2009 (approval for conducting the research was granted by the Independent Research Ethics Committee, Medical University of Gdansk no. NKEBN/400-2008/2009). All subjects were tested on a one-off-basis. Each person was provided with explanations of the research purpose and then gave their direct verbal consent to participate in the research. The research was anonymous. Before the start of classes, participants were asked to fill in the following questionnaires: a survey for measurement of Couvade Syndrome, and the Empathic Sensitiveness Scale (SWE). The respondents could voluntarily give information on the number of children, marital status, age and education.

The subjects completed the test on their own, without consultation with their female partners. The test lasted an average of 15 minutes. It should be noted that one group comprised from a few up to less than twenty men participating - in line with the schedule - in some antenatal classes only. Therefore, the research involved male participants from several groups. The group consisted of all men participating in the classes in the schools we entered. All men who were asked to participate in the study gave their verbal consent.

The research involved 143 expectant fathers (all fathers who agreed to participate in the study). All subjects attended antenatal classes. The female partners of the subjects were in their third trimester. No payment was offered to participants.

\section{Methods}

A personality questionnaire and a survey were used to measure empathy and Couvade Syndrome:

1. The Empathic Sensitiveness Scale (SWE) (24) used to measure empathy in three dimensions:

- cognitive empathy: taking someone else's perspective in everyday social situations;
- emotional empathy: emphatic concern (sharing others' feelings, compassion for them) and personal distress (the tendency to take on other people's negative emotions when they experience psychological discomfort).

In previous research, and according to the proposed model [26], taking the perspective of others and emphatic concern correlated positively with emotional intelligence, kindness shown to others, extraversion, or co-occurred with lower aggressiveness. Empathic concern also co-occurred with a tendency to worry or experience apprehension. Personal distress co-occurred with emotional instability, anxiety, neuroticism, negative reactions to change, or even verbal aggression [24-26]. The reliability indices obtained (Cronbach's alpha for ET $(E C)=0.78$; for OP $(P D)=0.78$; for PP (TP) $=0.74$; [24] and validity analyses indicate that the SWE is an adequate tool to measure empathy. The SWE consists of 28 statements with a five-grade response scale.

2. The survey to measure Couvade Syndrome includes a set of 16 symptoms identified by (19) and translated into Polish. The subjects received the following instructions:

"Often, the partner of a pregnant woman experiences several health-related symptoms that impede daily functioning. Please read the following list of health-related symptoms and put ' $X$ ' in one of the columns next to each symptom, depending on the frequency with which you experienced/have experienced such symptoms since your partner became pregnant. Please be frank and honest. NOTE!!! Please only consider the symptoms whose origin cannot be unambiguously traced."

A four-grade response scale was used. The tool used is characterized by a high degree of reliability: Cronbach's alpha $=0.87$.

\section{Results}

Out of 130 men that stated their age, two age groups were the most numerous: 71 men of 26-30 YOA and 51 men of 3140 YOA. One hundred and twenty six stated their education. Of them, 67 were university graduates, 55 had secondary education and 4 - basic vocational education. For the majority of men this was their first baby.

According to the research problem presented above, the research examined the structure of Couvade Syndrome and its prevalence in the study group, thus trying to answer the first research question. Average values for the group of 143 men show that the subjects actually do not notice symptoms of Couvade Syndrome in themselves. However, out of the set of conditions given, they most frequently experience (the average above 1.5) symptoms that are commonly linked with the syndrome, namely those related to weight (weight gain, changes in appetite and flatulence) (Table 1, Figure 1). 
Table 1. Frequency of symptoms of Couvade Syndrome among male subjects.

\begin{tabular}{ccc}
\hline $\begin{array}{c}\text { Couvade Syndrome } \\
\text { symptoms }\end{array}$ & $\begin{array}{c}\text { Average } \\
\text { for the group }\end{array}$ & $\begin{array}{c}\text { Standard } \\
\text { deviation }\end{array}$ \\
\hline Nausea & 1.259 & .636 \\
\hline Vomiting & 1.182 & .539 \\
\hline Abdominal pain & 1.448 & .748 \\
\hline Flatulence & 1.587 & .883 \\
\hline Changes in appetite & 1.601 & .873 \\
\hline Weight gain & 1.839 & 1.079 \\
\hline Weight loss & 1.252 & .587 \\
\hline Intestinal problems & 1.420 & .764 \\
\hline Toothaches & 1.350 & .684 \\
\hline Skin problems & 1.413 & .735 \\
\hline Leg cramps & 1.273 & .630 \\
\hline Fainting & 1.077 & .337 \\
\hline Weakness & 1.273 & .559 \\
\hline Colic & 1.105 & .388 \\
\hline Diarrhoea & 1.350 & .695 \\
\hline Constipation & 1.224 & \\
\hline & & .549 \\
\hline
\end{tabular}

It is worth noting that $28 \%$ of men $(n=40)$ had not noticed any symptoms of Couvade Syndrome in themselves.

Then, the links were analysed between Couvade Syndrome and the level of male empathy (in a multidimensional sense). In this way, the authors started to search for an answer to the next research question.
117 expectant fathers completed the Empathic Sensitiveness Scale [24]. 26 men did not complete the test, or they omitted some questions from the questionnaire, therefore their scores were not computed. Correlation analysis was carried out with calculation of Spearman's rho in order to verify whether the individual components of empathy co-occur with the symptoms of Couvade Syndrome experienced. The results of the analysis indicate that the only component that positively correlates with Couvade Syndrome is personal distress, i.e. the tendency to take on the negative emotions of others (Spearman's rho for OP (PD)-couvade $=0.229 ; \mathrm{p}<0.05$ (one-sided significance)) .

Because the distribution of the Couvade Syndrome variable diverged from the normal $(Z=4.136 ; p<0.001)$, the results on that dimension were dichotomized over the median, and such a restated variable was included in the multiple linear regression analysis. The analysis indicated that empathy was a significant predictor of Couvade Syndrome but this only explained $7 \%$ of its symptoms' variance $(R=0.273$, $R$-square $=0.074$; adjusted $R$-square $=0.049, F[3,109]=2.917, p<0.05)$. Again, personal distress was an independent predictor of Couvade Syndrome (Beta correlation=0.262; $p<0.01$ ).

These results suggest that, in accordance with previous reports from the syndrome research, emotionally sensitive or prone to distress men may experience the couvade. Additional analyses did not reveal the importance of age and education in a tendency to experience Couvade Syndrome.

\section{Discussion}

Findings of the research on prevalence of the Couvade Syndrome indicate that although individual symptoms, as defined by Lipkin and Lamb, are rare, most men (72\%) still experience at least one of them during their partner's pregnancy. As our research indicate, predispositions towards the syndrome include some personality traits associated with

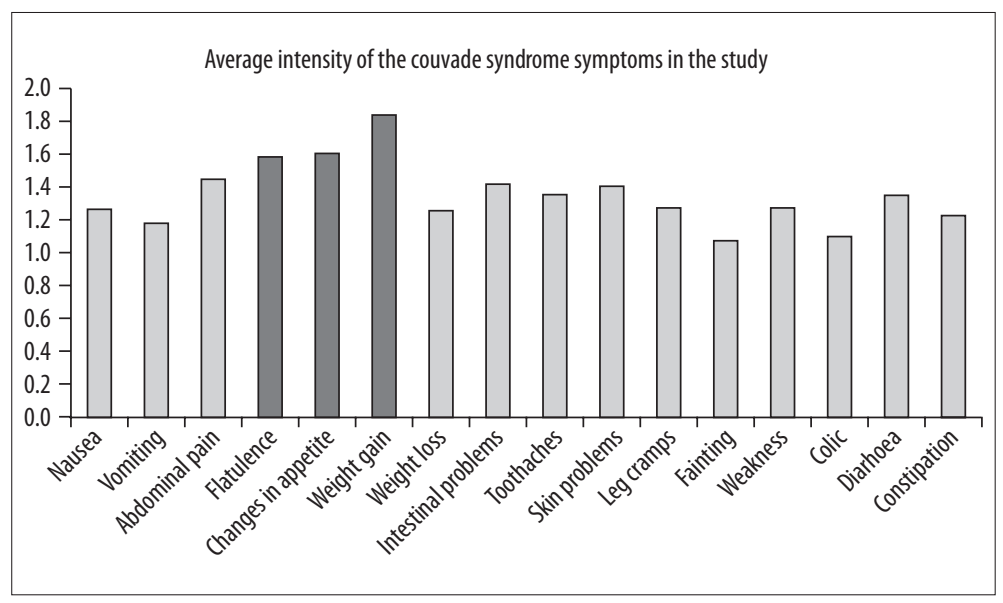

Figure 1. Frequency of Couvade Syndrome symptoms among male subjects. 
negative emotionality and neuroticism. Namely, men who have a tendency to take on the negative emotions of others, feel discomfort in response to those observed, the unfavourable situation of somebody else, experience stress related to the suffering of others, all have a greater tendency to experience Couvade Syndrome.

We might conclude that in our studies there is an evidence for compathy displayed by participants as defined by [10]. However, as Morse et al. [10] indicate, empathy and compathy require control of the responses to another's situation, in order not to be overwhelmed by distress. In the earlier research by Kaźmierczak [26], personal distress correlated negatively with empathic acceptance of somebody else's perspective, thus suggesting that we are dealing here with sensitivity to other people's emotions and ability to be affected by them but often without any effort to understand somebody else's situation. This type of empathy may pose a threat to the socalled egocentric deviation [11], where it is the man who experiences some pregnancy-related inconveniences, so a fundamental empathic process takes place of becoming infected with somebody else's reactions, resulting in the self-centred rather than female partner-centred attitude.

These findings also confirm the theses of Brennan, MarschallLucette, Ayers and Ahmed [27], who draw attention to the uncertainty and stress experienced by men who are preparing themselves for the role of father. It seems that modern men are intuitively looking for the strategy to participate in the rites associated with expecting the child, the manifestation of which is Couvade Syndrome. Fathers attend antenatal classes with their partners, visit a doctor but also renovate a flat or look for better employment. All these actions are an expression of the man's need for active co-participation in expecting the child. The childbirth is a culmination of the preparatory period, which is now time-shared by both parents. The renaissance of childbirths where both partners are present may be considered a renewal of the couvade ritual. As such, it is beneficial for both partners, and not least for the newborn who can count on the support of both parents.

\section{Limitations of the research}

The following major limitations of the research can be distinguished:

1. Omission of psychological symptoms of the syndrome.

2. Average size of the study group.

3. Lack of representativeness of the study group - fathers participating in the research were selected merely based on their participation in antenatal classes, which may interfere with the research findings.

\section{Conclusions}

Entering the role of father is often regarded as having to fulfill certain obligations - being supportive towards a female partner, and helping her in the process of pregnancy and labour. However, a man does not have to be an observer of this process. The awareness of becoming a father might lead to various reactions amongst men, including experiencing Couvade Syndrome. Today, Couvade Syndrome is not associated with social status, while the role of a man in labour is often undefined. For years this situation has been reflected in midwives and doctors' behaviours towards fathers in the act of childbirth. Men did not participate in the process of pregnancy and labour, which were regarded as women's issues. This changed in the 1970s, when fathers started to display their dissatisfaction with such a situation, and tried to create ways to engage in the process of increasing their family from the beginning. Couvade Syndrome became one of the signs of their deep emotional engagement in pregnancy and childbirth. Therefore, those fathers have become the active partners of expectant mothers. They are interested in their partners' needs and help in the process of communication between women and medical staff during labour. However, we should not forget that because of the pervasive trend to engage fathers in labour, there are those who are mostly concerned with their own psychological situation, and do not concentrate on a mother's feelings. They act egocentrically, not empathically, displaying the negative side of Couvade Syndrome. Processes which are associated with Couvade Syndrome, might be also viewed as a part of creating a new identity - the self as a father. Therefore, those men experience a stressfull moment in their lives, which redefines their perception of themselves. And it is well documented in the subject literature that identity issues should be analyzed in situations of personal crises [28-30]. Further studies on expectant fathers should be conducted in this direction.

Midwives might communicate with such fathers effectively, because men treat them as experts, but a woman's desires might be omitted, causing her dissatisfaction. Therefore, there is a need to define the role of a father during the process of pregnancy and labour. Antenatal classes might serve as the beginning of the formal way to do this, followed by a family labour (if it is possible from a medical standpoint), where fathers are the active partners of mothers, ones who focus on a woman's needs, supporting the communication between her and the midwife. 


\section{References:}

1. O'Brien M: Fathers, parental leave policies, and infant quality of life: in ternational perspectives and policy impact. The Annals of the American of Political and Social Science; 2009; 624: 190-213

2. Stangret M: [Dad with Couvade Syndrome]. Available from: http://wiadomosci.gazeta.pl/Wiadomosci/1,80279,2949921.html 2005 (in Polish)

3. Summersgill P. (ed.): [Couvades and looping the fatherhood]. In: Nowoczesne Położnictwo. Alexander J et al., Wyd. Lek. PZWL, Warsaw, 1995; 4: 111-13 (in Polish)

4. Tylor EB: Researches into the early history of mankind and the development of civilization, $2^{\text {nd }}$ ed., John Murray, London, 1865

5. Murphy RL: Couvade: The Pregnant Male. J Perinat Educ, 1992; 1(2): 13-18

6. Munroe RL, Munroe RH, Whiting JWM: The couvade: a psychological analysis. Ethos, 1973; 1(1): 30-74

7. Broude GJ: Rethinking the couvade: cross-cultural evidence. American Anthropologist, 1988; 90(4): 902-11

8. Kiselica MS, Scheckel S: The Couvade Syndrome (sympathetic pregnancy) and teenage fathers: A brief primer for school counsellors. School Counsellor, 1995; 43(1): 42-52

9. Brennan A, Ayers S, Ahmed H, Marshall-Lucette S: A critical review of the Couvade Syndrome: the pregnant male. J Reprod Infant Psychol, 2007; 25(3): 173-89

10. Morse JM, Mitcham C, van der Steen WJ: Compathy or physical empathy: implications for the caregiver relationship. J Med. Humanit, 1998; 19(1): 51-65

11. Hoffman ML: Empathy and moral development. Implications for caring and justice. Cambridge University Press, New York, 2003

12. Radhakrishnan R, Satheeshkumar G, Chaturvedi SK: Recurrent delusions of pregnancy in a male. Psychopathology, 1999; 32(1): 1-4

13. Eisner B: Notes on the mysterious phenomenon of loading. The Journal of Mind-Body Health, 1995; 11(2): 55-58

14. Kitzinger S: Birth over thirty. Sheldon Press, London, 1983

15. Kitzinger S: Pregnancy and childbirth. Michael Joseph, London, 1983
16. Richman J: Men's experiences of pregnancy and childbirth. In: Mc Kee L O'Brien M (eds.), The father figure. Tavistock, London, 1982

17. Healy P: Where fathers can cry, too. The Independent, 1990; April 2, 14

18. Laplante P: The Couvade Syndrome. The biological, psychological, and social impact of pregnancy on the expectant father. Canadian Family Physician, 1991; 37: 1633-60

19. Polomeno V: Health Promotion for Expectant Fathers: Part I. Documenting the Need. J Perinat Educ, 1998; 7(1): 1-8

20. Lipkin M, Lamb GS: The couvades syndrome: an epidemiological study. Ann Intern Med, 1982; 96: 509-11

21. Romito P: The humanizing of childbirth: the response of medical institutions to women's demand for change. Midwifery, 1986; 2: 135

22. Chapman L: Searching expectant fathers' experiences during labour and birth. J Perinat Neonatal Nurs, 1991; 4(4): 21

23. Jordan P: Labouring for relevance: expectant and new fatherhood. Nurs Res, 1990; 39: 11-16

24. Kaźmierczak M, Plopa M, Retowski S: [The Empathic Sensitiveness Scale]. Przegląd Psychologiczny, 2007; 50(1): 9-24 (in Polish)

25. Davis MH: [Empathy. A social Psychological Approach]. Gdańsk: GWP, 2001 (in Polish)

26. Kaźmierczak M: [Empathy in marital relations. The psychological perspective]. Gdańsk, Wyd. UG, 2008 (in Polish)

27. Brennan A, Marshall-Lucette $\mathrm{S}$, Ayers $\mathrm{S}$, Ahmed $\mathrm{H}$ : A qualitative exploration of the Couvade Syndrome in expectant fathers. J Reprod Infant Psychol, 2007; 25(1): 18-39

28. Pąchalska M, Wachowicz N, Bidzan M: Disintegration of higher language functions in patients with right hemisphere damage. Acta Neuropsychologica, 2010; 8(2): 68-98

29. Pachalska M, MacQueen BD, Kaczmarek B et al: A case of "Borrowed Identity Syndrome" after severe traumatic brain injury. Med Sci Monit, 2011; 17(2): CS18-28

30. Oleś PK: Psychologia człowieka dorosłego. Ciągłość - zmiana - integrac ja. [Psychology of adult man. Continuity - change - integration]. Warsaw: PWN, 2012 